\title{
ldentificação e priorização dos fatores críticos de sucesso na implantação de fábrica digital
}

\author{
Paulo Cesar De Carli ${ }^{\mathrm{a}, *}$, Maurício César Delamaro ${ }^{\mathrm{b}}$, Valério Antonio Pamplona Salomon ${ }^{\mathrm{c}}$ \\ a,**decarli.gta@uol.com.br, UNESP-FEG, Brasil \\ bdelamaro@feg.unesp.br, UNESP-FEG, Brasil \\ 'salomon@feg.unesp.br, UNESP-FEG, Brasil
}

\begin{abstract}
Resumo
Fábrica digital é um conceito que melhora a colaboração entre os processos de desenvolvimento do produto. Apesar dos benefícios trazidos por esse conceito, falhas podem ocorrer na sua implantação. Este artigo tem por objetivo apresentar os fatores críticos de sucesso na implantação de um projeto de fábrica digital em uma empresa brasileira. Esses fatores foram identificados por meio de uma pesquisa exploratória em implantações de sistemas como o Enterprise Resource Planninge Product Lifecycle Management, entre outros. Depois disso, os fatores foram priorizados, utilizando-se os métodos Delphi e Analytic Hierarchy Process, por profissionais de empresas que implantam projetos de fábrica digital, no Brasil e exterior. Foram identificados nove fatores, sendo os cinco de maior prioridade: apoio e comprometimento contínuo da alta gerência; abrangente reengenharia do negócio; parceiros com conhecimento e experiência; participação e comprometimento do usuário; e adequado papel do líder do projeto.
\end{abstract}

Palavras-chave

Fábrica digital. Fatores críticos de sucesso. Método Delphi. AHP.

\section{Introdução}

De tempos em tempos a inovação reaparece como foco de estratégias de crescimento das organizações. Isso pode abranger um grande espectro, incluindo tecnologias, bens, processos e, por vezes, empreendimentos inteiros. Em meio a diferentes cenários e aos vários tipos de inovação que se apresentam, as empresas enfrentam o conflito entre preservar as receitas vigentes, garantindo o sucesso presente, e investir em novos conceitos que podem ser imprescindiveis para o sucesso futuro.

De acordo com McAfee (2006), economistas e especialistas em história empresarial concordam que a tecnologia da informação (TI) é a última de uma série de tecnologias de uso geral, as General Purpose Technologies, que representam inovações tão importantes que causam saltos no ritmo normal de progresso de uma economia.

Empresas no mundo todo adotaram a $\mathrm{Tl}$ como forma de se buscar melhores resultados. Uma constatação é que em 1987 o investimento de empresas americanas em $\mathrm{Tl}$, por funcionário, foi em média de US\$ 1.500. Em 2004, tal cifra mais que triplicou, atingindo US\$ 5.100 por funcionário (MCAFEE, 2006).

A fábrica digital aparece, nesse contexto, como uma inovação de $\mathrm{Tl}$ que busca otimizar os processos de desenvolvimento do produto pela introdução de novos processos e softwares que proporcionam maior colaboração com o desenvolvimento dos processos de manufatura.

Fábrica digital, também tratada por manufatura digital, é um termo que tem sido usado há anos por vendedores de softwares e de máquinas. Mas só recentemente esse conceito se tornou disponível a quase qualquer empresa da cadeia de suprimentos. As maiores empresas automotivas já investiram fortemente nesse conceito, transformando muitos de seus processos em processos digitais ao invés de baseados em papel (DALTON-TAGGART, 2005).

Há anos, sistemas como Finite Element Analysis (FEA) e Computer Aided Manufacturing (CAM) frequentemente necessitavam de usuários 
com mentes altamente científicas e treinadas e significativos valores de investimentos. Na década de 90, esses sistemas se tornaram, financeiramente, mais acessíveis e práticos, mesmo no chão de fábrica. As visualizações de arquivos no sistema Computer Aided Design (CAD) chegaram em meados da década, permitindo a visualização de dados de projetos em três dimensões, sem a necessidade de adquirir plataformas CAD de altos preços. Isso permitiu que milhares de empresas passassem a visualizar e a trocar documentos eletrônicos, iniciando o caminho para a manufatura digital (DALTON-TAGGART, 2005).

Comprimir o ciclo de desenvolvimento de produtos significa muito para empresas que frequentemente operam sob pequenas margens de lucro. Com a última geração de softwares de manufatura digital e de Product Lifecycle Management (PLM), fabricantes da indústria automobilística e aeroespacial têm a oportunidade de reduzir grandemente o time-to-market de novos produtos, assim como cortar custos. Nos últimos anos, os sistemas de manufatura digital cresceram, especialmente com essas indústrias, motivando o aparecimento de soluções mais capazes, que oferecem simulações realistas de layouts produtivos, processos, linhas de montagens, células de robôs e controles de automação industrial (WAURZYNIAK, 2007).

Para Kuehn (2006), a fábrica digital é um conceito que possui caráter de integração, melhorando produtos e processos de engenharia de produção. A simulação é a tecnologia-chave nesse conceito, em que diferentes tipos de simulação, como eventos discretos ou simulação animada em três dimensões, podem ser aplicados em modelos virtuais para várias tarefas e estágios de planejamento, com o objetivo de melhorar os produtos e o planejamento dos processos em todos os níveis. Produtos, processos e recursos são testados em uma fábrica virtual para, quando livres de erros, serem usados na fábrica real (KUEHN, 2006). Essas características da fábrica digital permitem que as empresas introduzam antes seus produtos no mercado, como pode ser visto na Figura 1. Outro benefício importante, apresentado na mesma Figura 1, é a eliminação dos erros operacionais, uma vez que os processos foram testados e são conhecidos logo na fabricação dos primeiros produtos.

Em outras palavras, o $C A D$ define o que será feito, a manufatura digital como será feito e, finalmente, para completar a cadeia, o Material Requirements Planning (MRP) estabelece quando será feito.
A fábrica digital integra os seguintes processos:

- Desenvolvimento, teste e otimização do produto;

- Desenvolvimento e otimização dos processos de produção;

- Projeto e melhoria da planta;

- Planejamento e controle das operações produtivas.

Um dos aspectos maisimportantes da manufatura digital, descreve Rowe (2006), é o repositório central de dados, exclusivo para a manufatura digital, tal qual o existente para o Product Data Management (PDM), para o gerenciamento dos dados do desenvolvimento do produto. A manufatura digital utiliza dados da estrutura de materiais de engenharia, Engineering Bill of Materials (EBOM), para criar a estrutura de materiais de produção, Manufacturing Bill of Materials (MBOM) e a estrutura de processos, Bill of Processes (BOP). Essas estruturas, mais o gerenciamento dos recursos produtivos - tais como ferramentas, máquinas, centros de trabalho, operadores humanos e robôs -, geram dados agrupados em produtos, processos e recursos da planta produtiva, que são criados e mantidos no repositório central de dados.

De acordo com Slansky (2006), assim como as ferramentas de modelo digital (também conhecido como digital mock-up) permitem aos engenheiros desenvolver modelos virtuais do produto, as ferramentas de manufatura digital permitem aos engenheiros de manufatura visualizar a operação dos processos produtivos. Com o digital mock-up, os engenheiros de projeto podem simular os encaixes entre superfícies, restrições a fixações, montagens de componentes, pontos de interfaces e mesmo movimentos mecânicos para verificar interferências entre estruturas. Pela simulação, muitos erros de projeto são evitados, e melhorias no produto são feitas. Mais ainda, tempo considerável e mão de obra são reduzidos pela eliminação dos protótipos físicos para validar o projeto do produto.

No Brasil, uma das empresas que têm conseguido significativos resultados com a implantação da fábrica digital é a Volkswagen. Segundo Pavani (2007), no mercado automotivo, onde a pressão por lançamentos é constante, os carros devem chegar mais rápido, com qualidade e preço que garantam rentabilidade à montadora e a seus acionistas. Uma solução de simulação tridimensional aplicada à estamparia de peças na Volkswagen mostra como a $\mathrm{Tl}$ pode ajudar a reduzir os custos e o tempo de resposta a essa pressão. "Já conseguimos com o projeto uma economia de 1 milhão de reais, uma vez que os processos e os testes físicos passaram a ser realizados virtualmente", afirma Vagner Montagner, 


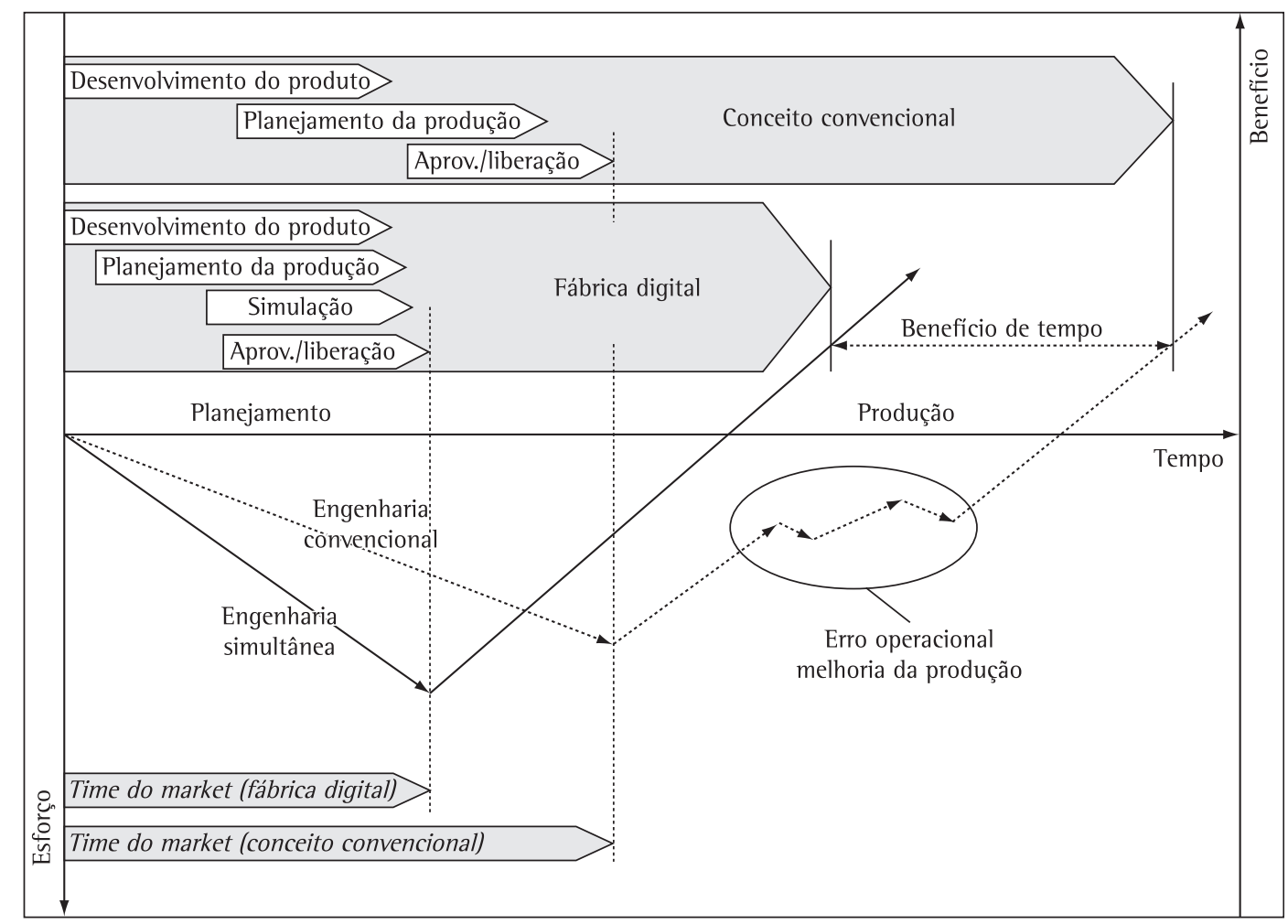

Figura 1. Benefício e esforço na fábrica digital. Fonte: adaptado de Kuehn (2006).

ClO da Volkswagen do Brasil, em entrevista realizada por Pavani (2007). 0 projeto denominado "Fábrica Digital” é uma iniciativa conjunta entre a $\mathrm{Tl}$ e a engenharia da montadora. Afirma Montagner em sua entrevista que "...o alto grau de competitividade da indústria automobilística imprime ao projeto um caráter estratégico, pois tem foco no core business". Segundo ele, a simulação permite reduzir os custos de desenvolvimento e produção de novos carros. A ideia é fazer com que a tecnologia viabilize a máxima simultaneidade entre o desenvolvimento de um protótipo e o processo de fabricação em larga escala.

Porém, a implantação da fábrica digital pode não ser uma tarefa fácil. Muitos autores relatam casos de insucessos nas implantações de sistemas. Falhar em aprender com as implementações de sistemas já realizadas é um problema comum (KRASNER, 2000). Esteves e Pastor (2001) relatam que, apesar dos benefícios que podem ser conseguidos com a implementação de sistemas Enterprise Resource Planning (ERP), existem evidências de falhas em projetos relacionados a esse tipo de implementação. Frequentemente, gerentes de projeto têm foco nos aspectos técnicos e financeiros e negligenciam em considerar as questões não técnicas. De acordo com os autores, para resolver esse problema alguns pesquisadores estão utilizando a abordagem dos fatores críticos de sucesso (FCS).

Neste artigo, para a identificação dos FCS aplicáveis à implantação do projeto Fábrica Digital, utilizou-se o caso de implantação da Empresa A, assim definida neste trabalho por questões de confidencialidade de informações. Procurou-se buscar o aprendizado disponível na literatura sobre implantações de sistemas ERP, PLM e de sistemas de informação em geral, uma vez que até o presente momento não foi encontrada literatura específica sobre a implantação de tal projeto.

São duas as contribuições pretendidas com este artigo. A primeira tem foco acadêmico, buscando disseminar os conceitos acerca da fábrica digital, ricos para várias disciplinas, especialmente para a Engenharia de Produção, uma vez que existem poucas informações sobre esse assunto e implantações de projetos dessa natureza, principalmente no Brasil. A segunda contribuição está relacionada aos resultados práticos da pesquisa. Depois de identificados e priorizados, os FCS podem ser utilizados por gerentes de projetos de fábrica digital e outros na elaboração de estratégias que minimizem os riscos de implantação. 
Na seção 2 são apresentados a metodologia da pesquisa e os métodos empregados; nas seções 3 e 4, os resultados obtidos; na seção 5, comentários sobre os resultados apresentados, assim como as recomendações para futuros trabalhos.

\section{Metodologia}

Este trabalho seguiu as etapas representadas pela Figura 2.

Como primeiro passo, foi gerado o embasamento teórico sobre fábrica digital, FCS, métodos Delphi e AHP, por meio de um levantamento bibliográfico sobre esses temas. Em especial, a revisão bibliográfica sobre FCS na implantação de sistemas permitiu a identificação dos FCS aplicáveis ao projeto Fábrica Digital.

Um questionário interno foi aplicado a especialistas da Empresa A para a validação desses FCS, ao mesmo tempo em que foram definidas as fases de implantação do projeto.

Depois de agrupados, cada FCS teve sua importância relativa definida durante a implantação do projeto. Nesta etapa, foi utilizado o método Delphi, para obter as opiniões de 17 especialistas em projetos de fábrica digital, da Empresa A e de outras três empresas, e o método AHP, para determinar o nível de importância relativa dos FCS. Devido a questões de confidencialidade de informações, as

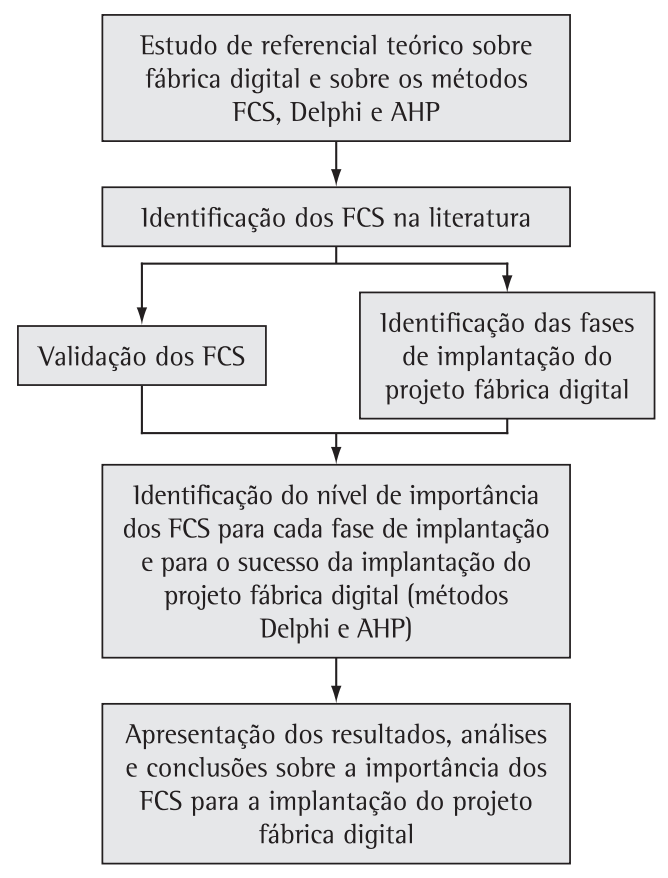

Figura 2. Etapas da pesquisa. quatro empresas envolvidas neste trabalho são tratadas conforme a seguir:

- Empresa A - Empresa nacional de grande porte, com ênfase na cadeia de suprimentos de manufatura. Tem experiência comprovada em projeto, fabricação, comercialização e pós-venda, distribuindo seus produtos pelos cinco continentes. A implantação do projeto Fábrica Digital em curso nessa empresa foi utilizada como estudo de caso;

- Empresa B - Empresa nacional de grande porte, também com grande destaque na cadeia de suprimentos de manufatura. Pertencente a um grupo europeu. Seus produtos são consumidos pelo mercado interno e também pelo mercado internacional.

- Empresa C - Empresa europeia de grande porte. Projeta, fabrica, comercializa e presta serviços pós-venda. Também tem ênfase na cadeia de suprimentos de manufatura. Seus produtos são utilizados no mundo todo;

- Empresa D - Empresa nacional, pertencente a um grupo europeu, provedora de softwares e de serviços de implantação de fábrica digital.

Por meio dos resultados individuais de cada um dos 17 respondentes, chegou-se ao resultado representativo do grupo, o que permitiu a análise, as conclusões e as considerações sobre a importância dos FCS para o projeto Fábrica Digital.

Com o objetivo de permitir uma melhor compreensão dos diferentes métodos e tipos de pesquisa, Diehl e Tatim (2004) apresentam uma classificação segundo as bases lógicas da investigação, a abordagem do problema, o objetivo geral, o propósito e o procedimento técnico da pesquisa. Essa classificação não deve ser considerada de forma rígida, uma vez que algumas pesquisas, em função de suas características, não se limitam facilmente a um ou a outro modelo. 0 desenvolvimento deste trabalho está de acordo com essa classificação.

Segundo as bases lógicas de investigação, o método deste artigo é classificado como fenomenológico porque se preocupou com a descrição direta da realidade como ela é, na medida em que buscou as opiniões dos especialistas por meio da expressão das suas experiências próprias, adquiridas em implantações de projetos. As opiniões foram estudadas tal como são percebidas por eles, sem qualquer interferência.

A forma de abordagem do problema é qualiquantitativa. Os resultados sobre as prioridades dos FCS foram obtidos inicialmente utilizando-se uma abordagem qualitativa para a coleta dos julgamentos subjetivos individuais dos especialistas, que contaram com suas experiências 
e conhecimentos sobre implantação de projetos. Depois, para a determinação do resultado representativo do grupo, foram utilizadas técnicas estatísticas como a média geométrica, porcentagem e os cálculos do AHP, com o objetivo de quantificar os valores das prioridades dos FCS para o sucesso da implantação.

Do ponto de vista do objetivo geral, este artigo utilizou a pesquisa exploratória porque buscou gerar maior conhecimento e familiaridade sobre os FCS aplicáveis a um projeto de implantação de fábrica digital. Também, porque envolveu levantamento bibliográfico e a obtenção de dados de pessoas que possuem conhecimento e experiência prática com o problema pesquisado.

Quanto ao procedimento técnico, a pesquisa realizada é bibliográfica, levantamento, estudo de caso e pesquisa-ação. É bibliográfica, à medida que ao ser elaborada recorreu a livros, teses, dissertações e artigos publicados. É levantamento porque utilizou questionamentos diretos a especialistas para conhecer suas opiniões sobre as fases de implantação e sobre os FCS. É um estudo de caso porque buscou o estudo aprofundado dos FCS para a implantação do projeto Fábrica Digital, utilizando o projeto em andamento na Empresa A. É uma pesquisaação porque buscou estabelecer a associação dos resultados com ações que objetivam resolver as principais questões relacionadas à implantação da fábrica digital e contou com o envolvimento de um dos autores deste trabalho na implantação.

\subsection{Fatores críticos de sucesso}

Desde a década de 70 , um problema comum enfrentado por várias empresas é a dificuldade que os administradores têm em obter as informações que realmente necessitam para tomar suas decisões a partir dos sistemas de informação existentes (LAURINDO, 2002). Rockart (1979) analisou essa dificuldade e propôs uma abordagem para serem concebidos os sistemas de informações gerenciais (SIG), baseada na definição pelos próprios gerentes sobre suas necessidades de informação. Essa abordagem tem por foco os FCS: " $O$ número limitado de áreas nas quais os resultados, se satisfatórios, asseguram o desempenho competitivo bem-sucedido para a organização".

A partir da introdução desse conceito, as palavras "fatores críticos de sucesso" começaram a aparecer nos vários níveis da hierarquia gerencial. Atualmente, dá-se o nome de FCS a uma relação de itens que devem ser observados durante o planejamento, execução e controle de um projeto, para que seus resultados sejam alcançados.
A implantação da fábrica digital, além de demandar grandes esforços nas mudanças dos processos das empresas, envolve expressivos valores de investimentos. Para que os resultados esperados na implantação, relativos a escopo, custos, prazos e qualidade sejam atingidos é necessário um criterioso planejamento de implantação, que considere os riscos potenciais envolvidos.

Uma abordagem capaz de auxiliar nessa tarefa é justamente a dos FCS. É comum definir-se FCS para a empresa como um todo ou para diferentes funções da empresa, como FCS de marketing, de manufatura, de projeto, dentre outros. Existe um acúmulo de experiências e de estudos sobre FCS em implantação de projetos, com destaque para: Alvarenga (2003); Carneiro (2006); Quintella, Rocha e Alves (2005); Tondaladinne, Gurram e Bachala (2006); Gambôa, Caputo e Bresciani Filho (2004); Caralli (2004); Esteves e Pastor (2000); Moraes e Laurindo (2003); Rocha (2005); Matos (2004) e Stackpole (2006).

\subsection{Método Delphi}

De acordo com Saaty e Peniwati (2008), num processo de tomada de decisão individual, as pessoas tão somente têm que concordar com elas mesmas; grupos, entretanto, geralmente têm problemas em chegar a um consenso. Portanto, todo progresso na tomada de decisão em grupo depende da habilidade de seus membros em trabalhar de forma unida e, para uma boa decisão, o grupo necessita ser diversificado e informado. Seus integrantes devem expor seus julgamentos independentes, não previamente coordenados, para permitir uma discussão criativa. Acima de tudo, para se obter uma decisão representativa para o grupo é necessário definir uma forma de sintetizar o julgamento de seus membros.

Originalmente desenvolvido por Norman Dalkey da RAND Corporation nos anos 50 para um projeto militar dos EUA, o método Delphi é um método para decisão em grupo, baseado em um processo interativo, que coleta e refina julgamentos anônimos de especialistas usando uma série de questionários e técnicas de análise interligados com feedback (SKULMOSKI; HARTMAN; KRAHN, 2007). Esse método se aplica como instrumento de pesquisa quando não existe completo conhecimento sobre um problema ou fenômeno, e funciona especialmente bem quando o objetivo é melhorar o entendimento de problemas, oportunidades, soluções, ou para desenvolver previsões.

Os questionários devem ser desenvolvidos com foco nos problemas, oportunidades, soluções ou previsões. Cada questionário subsequente é 
feito com base nos resultados dos questionários anteriormente respondidos. 0 processo é concluído quando a questão pesquisada é respondida: por exemplo, quando o consenso é alcançado, uma saturação teórica é conseguida, ou quando informações são suficientemente trocadas.

Skulmoski, Hartman e Krahn (2007) definem de maneira geral os passos esquematizados na Figura 3, sobre como o método Delphi tem sido usado em projetos de pesquisa:

0 Quadro 1 apresenta como o método Delphi tem sido usado para desenvolver, identificar, prever e validar em várias pesquisas. Observa-se neste quadro que, embora a quantidade de respondentes varie substancialmente, as rodadas para a obtenção do consenso final dos grupos não passam de 3.

\subsection{Método AHP}

A tomada de decisão com múltiplos critérios (MCDM, do inglês Multiple-Criteria Decision Making), como o próprio nome sugere, ocorre em situações em que se considera mais de um critério, por exemplo: custo, qualidade e atendimento.

0 método AHP, proposto pelo matemático americano Thomas L. Saaty, na década de 70, é um dos mais conhecidos e utilizados métodos de MCDM (COSTA, 2006). Pesquisa realizada por Wallenius et al. (2008) comprova que se trata do método de MCDM com mais publicações em periódicos científicos.

A escolha do AHP para utilização neste trabalho se deve, primeiramente, ao fato de ser um método de MCDM. 0 problema de decisão na identificação das prioridades dos FCS para o sucesso da implantação do projeto Fábrica Digital considera a avaliação de nove alternativas (FCS) à luz de cinco critérios (fases). Trata-se, portanto, de um caso de decisão pela análise multicritério.

Um fator importante na escolha do AHP é a estruturação do problema de decisão em níveis hierárquicos. Conforme Shimizu (2006), a construção e utilização de um modelo de estabelecimento de prioridades fundamentado no uso do AHP começam com a elaboração da hierarquia. Nessa etapa são identificados o objetivo global, os critérios e as alternativas. Em seguida, são coletados os julgamentos de valor emitidos por especialistas. Esses valores são agrupados em quadros de julgamentos que se comportam como matrizes recíprocas de comparação. Para esses julgamentos é feita uma análise da coerência, o que é uma das vantagens do AHP. Os dados desses julgamentos são sintetizados, o que permite 0 cálculo da prioridade de cada alternativa em relação ao foco principal. 0 princípio básico do AHP é a geração de um vetor de prioridades pelo cálculo do maior autovetor de cada matriz de comparação.

\section{Identificação dos FCS}

Para a utilização dos FCS na implantação do projeto Fábrica Digital foram executados os três passos descritos a seguir.

No primeiro passo foi elaborada uma lista de FCS, a partir de experiências em implantação de sistemas disponíveis na literatura, uma vez que não existem pesquisas direcionadas especificamente à implantação de projetos de fábrica digital. As referências utilizadas foram:

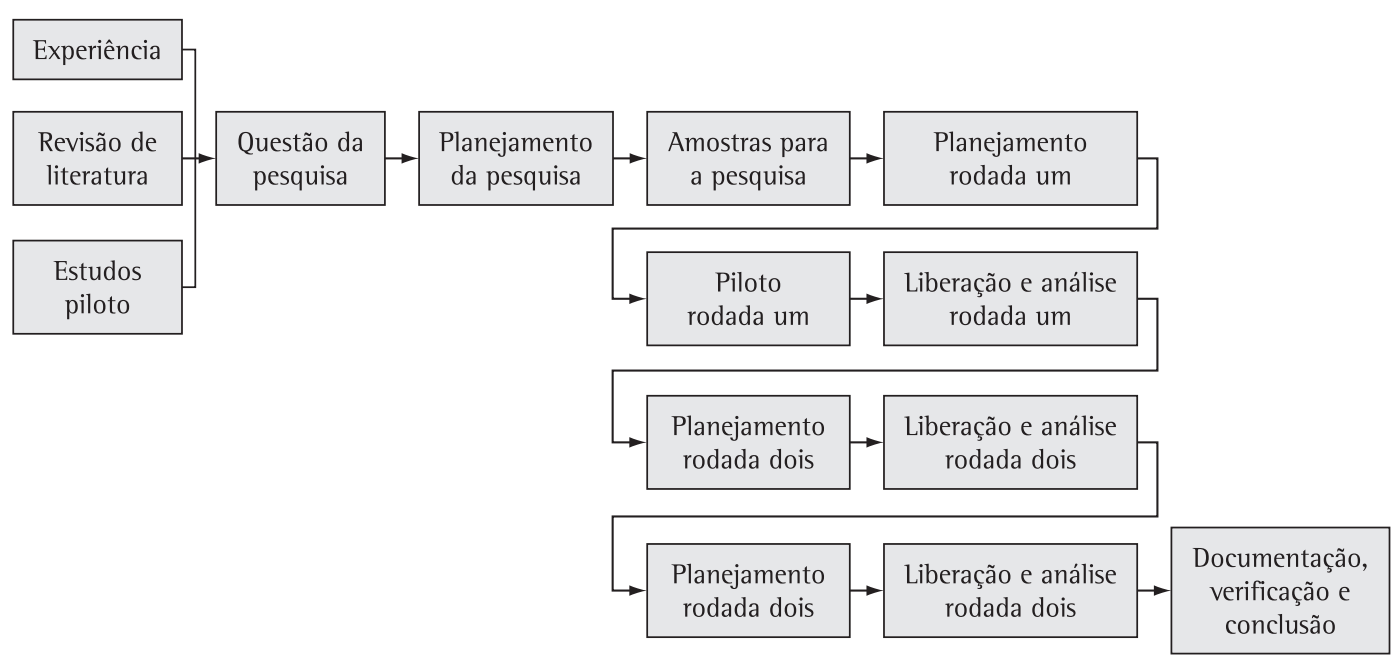

Figura 3. Método Delphi em três rodadas. Fonte: Adaptado de Skulmoski, Hartman e Krahn (2007). 
- Moraes e Laurindo (2003), que apresentam uma relação de fatores de risco aplicáveis a sistemas de informação. Keil et al. (1998), ao estudarem os riscos de projetos de sistemas de informação, utilizaram o método Delphi, o que levou à construção de uma lista dos fatores de risco em ordem decrescente de importância;

- Gambôa, Caputo e Bresciani Filho (2004), que indicam uma relação de FCS obtida por meio da pesquisa de FCS aplicáveis à implantações de sistemas ERP;

- Esteves e Pastor (2000), que também apresentam uma relação de FCS obtida por meio da pesquisa de FCS aplicáveis a implantações de sistemas ERP;
- Tondaladinne, Gurram e Bachala (2006), que mostram as principais questões a serem cuidadas para garantir o sucesso na implantação de sistemas PLM;

- Stackpole (2006), que aponta quais lições aprendidas na implantação de sistemas ERP são aplicáveis a sistemas PLM.

Nesta fase, todos os fatores identificados foram analisados e comparados para verificar a ocorrência de repetição deles entre as várias pesquisas. 0 resultado final foram 28 FCS, conforme mostrados no Quadro 2. Percebe-se que alguns FCS foram identificados por mais de um autor.

Quadro 1. Diversidade de aplicação do método Delphi.

\begin{tabular}{|c|c|c|c|}
\hline Estudo não em Tl/SI & Foco Delphi & Rodadas & Tamanho da amostra \\
\hline Gustafsonet al. (1973) & $\begin{array}{l}\text { Estimar eventos para investigar a precisão do } \\
\text { método Delphi. }\end{array}$ & 2 & 4 \\
\hline Hartman e Baldwin (1995) & Validar resultados de pesquisas. & 1 & 62 \\
\hline Czinkota e Ronkainen (1997) & $\begin{array}{l}\text { Análise de impacto das mudanças no ambiente } \\
\text { de negócios internacional. }\end{array}$ & 3 & 34 \\
\hline Kuo e Yu (1999) & $\begin{array}{l}\text { ldentificar critérios de seleção para parque } \\
\text { nacional. }\end{array}$ & 1 & 28 \\
\hline Nambisan et al. (1999) & $\begin{array}{l}\text { Desenvolver sistemática de mecanismos } \\
\text { organizacionais. }\end{array}$ & 3 & 6 \\
\hline Lam, Petri e Smith (2000) & $\begin{array}{l}\text { Desenvolver regras para um processo de } \\
\text { fundição cerâmico. }\end{array}$ & 3 & 3 \\
\hline $\begin{array}{l}\text { Roberson, Collins e Oreg } \\
(2005)\end{array}$ & $\begin{array}{l}\text { Examinar e explicar como a especificidade da } \\
\text { mensagem de recrutamento inflencia a atração } \\
\text { de interessados em trabalho nas organizações. }\end{array}$ & 2 & 171 \\
\hline Estudo em Tl/SI & Foco Delphi & Rodadas & Tamanho da amostra \\
\hline $\begin{array}{l}\text { Niederman, Brancheau e } \\
\text { Wetherbe (1991) }\end{array}$ & $\begin{array}{l}\text { Avaliação de executivos seniores de Sl para } \\
\text { determinar as mais críticas questões de SI dos } \\
\text { anos } 90 .\end{array}$ & 3 & 114,126 e 104 \\
\hline Duncan (1995) & $\begin{array}{l}\text { Indentificar e classificar os elementos críticos } \\
\text { de flexibilidade de infraestrutura de SI. }\end{array}$ & 2 & 21 \\
\hline $\begin{array}{l}\text { Brancheau, Janz e Wetherbe } \\
\text { (1996) }\end{array}$ & $\begin{array}{l}\text { Avaliação dos membros da Sociedade de } \\
\text { Sistemas de Informação (SIM) para determinar } \\
\text { as mais críticas questões de SI para o futuro } \\
\text { próximo. }\end{array}$ & 3 & 78,87 e 76 \\
\hline Nambisan et al. (1999) & $\begin{array}{l}\text { Desenvolver uma sistemática de mecanismos } \\
\text { de geração de conhecimento. }\end{array}$ & 3 & 11 \\
\hline Scott (2000) & $\begin{array}{l}\text { Classificar as questões de gerenciamento } \\
\text { tecnológico em projetos de desenvolvimento } \\
\text { de novos produtos. }\end{array}$ & 3 & 20 \\
\hline Wynekoop e Walz (2000) & $\begin{array}{l}\text { Classificar as mais importantes caracteristicas } \\
\text { de profissionais de } \mathrm{Tl} \text { de alta performance. }\end{array}$ & 3 & 9 \\
\hline Schmidt et al. (2001) & $\begin{array}{l}\text { ldentificar e classificar riscos de projetos de } \\
\text { desenvolvimento de software. }\end{array}$ & 3 & $\begin{array}{c}\text { Finlândia: } 13,13 \text { e } 13 \\
\text { Hong Kong: } 11,11 \text { e } 9 \\
\text { USA: } 21,21 \text { e } 9 \\
\end{array}$ \\
\hline Keil, Tiwana e Bush (2002) & $\begin{array}{l}\text { Classificar riscos de projetos de desenvolvimento } \\
\text { de software. }\end{array}$ & 3 & 15,15 e 10 \\
\hline Brungs e Jamieson (2005) & $\begin{array}{l}\text { ldentificar e classificar questões relacionadas } \\
\text { ao uso do computador nas questões legais } \\
\text { (computer forensics) }\end{array}$ & 3 & 11 \\
\hline
\end{tabular}


Quadro 2. Fatores críticos de sucesso e autores.

\begin{tabular}{|c|c|c|}
\hline & Fatores Críticos de Sucesso & Autores \\
\hline 1 & $\begin{array}{l}\text { Apoio e comprometimento contínuo da alta } \\
\text { gerência. }\end{array}$ & $\begin{array}{l}\text { Esteves e Pastor (2000); Moraes e Laurindo (2003); Gambôa, Caputo } \\
\text { e Bresciani Filho (2004); Stackpole (2006). }\end{array}$ \\
\hline 2 & $\begin{array}{l}\text { Gerenciamento efetivo da mudança ao longo do } \\
\text { projeto (Preparação das pessoas para a mudança). }\end{array}$ & $\begin{array}{l}\text { Esteves e Pastor (2000); Tondaladinne, Gurram e Bachala (2006); } \\
\text { Gambôa, Caputo e Bresciani Filho (2004); Stackpole (2006). }\end{array}$ \\
\hline 3 & Composição adequada do time do projeto. & $\begin{array}{l}\text { Esteves e Pastor (2000); Tondaladinne, Gurram e Bachala (2006); } \\
\text { Moraes e Laurindo (2003); Gambôa, Caputo e Bresciani Filho (2004); } \\
\text { Stackpole (2006). }\end{array}$ \\
\hline 4 & $\begin{array}{l}\text { Documentação da visão do projeto } \\
\text { (Planejamento, escopo, objetivos, organização, } \\
\text { papéis e responsabilidades). }\end{array}$ & Tondaladinne, Gurram e Bachala (2006). \\
\hline 5 & $\begin{array}{l}\text { Bom gerenciamento do escopo do projeto } \\
\text { (Comitê diretor para avaliar mudanças). }\end{array}$ & $\begin{array}{l}\text { Esteves e Pastor (2000); Tondaladinne, Gurram e Bachala (2006); } \\
\text { Moraes e Laurindo (2003); Gambôa, Caputo e Bresciani Filho (2004). }\end{array}$ \\
\hline 6 & Abrangente reengenharia do negócio. & Esteves e Pastor (2000); Tondaladinne, Gurram e Bachala (2006). \\
\hline 7 & Adequado papel do líder do projeto. & $\begin{array}{l}\text { Esteves e Pastor (2000); Gambôa, Caputo e Bresciani Filho (2004); } \\
\text { Stackpole (2006). }\end{array}$ \\
\hline 8 & $\begin{array}{l}\text { Desenvolvimento do projeto baseado em milestones } \\
\text { (Questões comerciais com parceiros atreladas ao } \\
\text { cumprimento de etapas). }\end{array}$ & Tondaladinne, Gurram e Bachala (2006). \\
\hline 9 & Participação e comprometimento do usuário. & $\begin{array}{l}\text { Esteves e Pastor (2000); Moraes e Laurindo (2003); Gambôa, Caputo } \\
\text { e Bresciani Filho (2004). }\end{array}$ \\
\hline 10 & Parceiros com conhecimento e experiência. & Stackpole (2006). \\
\hline 11 & $\begin{array}{l}\text { Tomadores de decisão capacitados e autorizados } \\
\text { (Agilidade nas decisões). }\end{array}$ & $\begin{array}{l}\text { Esteves e Pastor (2000); Gambôa, Caputo e Bresciani Filho (2004); } \\
\text { Stackpole (2006). }\end{array}$ \\
\hline 12 & $\begin{array}{l}\text { Adequado programa de treinamento } \\
\text { (Equipe projeto, equipe suporte e usuários). }\end{array}$ & $\begin{array}{l}\text { Esteves e Pastor (2000); Tondaladinne, Gurram e Bachala (2006); } \\
\text { Moraes e Laurindo (2003); Gambôa, Caputo e Bresciani Filho (2004). }\end{array}$ \\
\hline 13 & Customizações mínimas. & $\begin{array}{l}\text { Esteves e Pastor (2000); Tondaladinne, Gurram e Bachala (2006); } \\
\text { Gambôa, Caputo e Bresciani Filho (2004). }\end{array}$ \\
\hline 14 & $\begin{array}{l}\text { Adequada estratégia de implementação do projeto } \\
\text { (Entrada em operação, suporte). }\end{array}$ & Esteves e Pastor (2000); Tondaladinne, Gurram e Bachala (2006). \\
\hline 15 & Conhecimento do software. & Gambôa, Caputo e Bresciani Filho (2004). \\
\hline 16 & Testes de aceitação do software. & $\begin{array}{l}\text { Tondaladinne, Gurram e Bachala (2006); Gambôa, Caputo e } \\
\text { Bresciani Filho (2004). }\end{array}$ \\
\hline 17 & Adequada versão do software. & Esteves e Pastor (2000); Tondaladinne, Gurram e Bachala (2006). \\
\hline 18 & $\begin{array}{l}\text { Adequado conhecimento dos sistemas legados } \\
\text { (Migração dos dados). }\end{array}$ & $\begin{array}{l}\text { Esteves e Pastor (2000); Tondaladinne, Gurram e Bachala (2006); } \\
\text { Moraes e Laurindo (2003); Gambôa, Caputo e Bresciani Filho (2004). }\end{array}$ \\
\hline 19 & Adequada configuração do software. & Esteves e Pastor (2000). \\
\hline 20 & Tamanho e complexidade do projeto. & Moraes e Laurindo (2003). \\
\hline 21 & Arquitetura técnica/performance inadequados. & Gambôa, Caputo e Bresciani Filho (2004). \\
\hline 22 & Forte comunicação interna e externa ao projeto. & Esteves e Pastor (2000). \\
\hline 23 & Bugs do software. & Gambôa, Caputo e Bresciani Filho (2004). \\
\hline 24 & Equipe do projeto motivada. & $\begin{array}{l}\text { Esteves e Pastor (2000); Moraes e Laurindo (2003); Gambôa, Caputo } \\
\text { e Bresciani Filho (2004). }\end{array}$ \\
\hline 25 & $\begin{array}{l}\text { Consenso em buscar o resultado bom o suficiente } \\
\text { ao invés do resultado melhor disponível } \\
\text { (Por vezes inalcançável). }\end{array}$ & Stackpole (2006). \\
\hline 26 & $\begin{array}{l}\text { Infra-estrutura e instalações para o projeto } \\
\text { (Salas, computadores, redes). }\end{array}$ & Tondaladinne, Gurram e Bachala (2006); Moraes e Laurindo (2003). \\
\hline 27 & Confiança entre parceiros do projeto. & Esteves e Pastor (2000). \\
\hline 28 & $\begin{array}{l}\text { Utilização apropriada dos consultores } \\
\text { (Como, quando, quantos). }\end{array}$ & Esteves e Pastor (2000). \\
\hline
\end{tabular}

Fonte: Dados da pesquisa bibliográfica. 
0 segundo passo foram análise e validação dos FCS. Uma equipe formada por 21 profissionais da Empresa A, experientes em implantações de sistemas ERP, CAD, CAM, Computer Aided Engineering (CAE) e realidade virtual, analisou e validou os FCS. A validação foi realizada por meio da aplicação de um questionário, no qual cada respondente definiu o nível de importância de cada um dos 28 FCS, de acordo com as alternativas: muito importante, importante, pouco importante e não importante.

Com base nos resultados do questionário sobre o nível de importância de cada FCS aplicável à implantação do projeto Fábrica Digital, concluiu-se que todos os 28 itens levantados nas referências teóricas deveriam ser considerados na implantação desse projeto.

A maioria dos FCS foi considerada "muito importante" ou "importante". A questão 28 obteve a pior avaliação, com três julgamentos "pouco importante" e um "não importante", que somados correspondem a 19\% do total das respostas e, por isso, também foi considerada aplicável ao projeto.

0 resultado de 28 FCS aplicáveis à implantação do projeto Fábrica Digital representa uma quantidade de FCS superior às consideradas isoladamente pelos autores citados, em seus trabalhos sobre o assunto.

0 terceiro passo foi a análise das características desses FCS e o agrupamento dos mesmos em nove grupos, conforme apresentados no Quadro 3.

0 agrupamento foi baseado nas justificativas apresentadas a seguir e caracteriza-se como uma contribuição dos autores deste trabalho.

Conforme apresentado no quadro, o primeiro FCS - "apoio e comprometimento contínuo da alta gerência" - permaneceu sem alterações.

Ao segundo FCS - "gerenciamento efetivo da mudança ao longo do projeto" - foram acrescentados os FCS "adequado programa de treinamento" e "forte comunicação interna e externa ao projeto". Conforme Tondaladinne, Gurram e Bachala (2006), mudanças nos sistemas existentes provocam reações psicológicas em várias pessoas. Normalmente elas não entendem por que substituí-los, uma vez que funcionam tão bem e estão trabalhando com os mesmos durante tantos anos. Além disso, existe o desconforto de aprender a trabalhar com sistemas novos. Recomendam os autores que essas pessoas sejam convocadas a participar mais intensamente

Quadro 3. Fatores críticos de sucesso agrupados.

\begin{tabular}{|c|}
\hline Fatores Críticos de Sucesso \\
\hline 1. Apoio e comprometimento contínuo da alta gerência \\
\hline $\begin{array}{l}\text { 2. Gerenciamento efetivo da mudança ao longo do projeto (Preparação das pessoas para a mudança) } \\
\text { - Adequado programa de treinamento (Equipe projeto, equipe suporte e usuários). } \\
\text { - Forte comunicação interna e externa ao projeto. }\end{array}$ \\
\hline $\begin{array}{l}\text { 3. Abrangente reengenharia do negócio } \\
\text { - Customizações mínimas. } \\
\text { - Tamanho e complexidade do projeto. } \\
\text { - Consenso em buscar o resultado bom o suficiente ao invés do resultado melhor disponível (Por vezes inalcançável). }\end{array}$ \\
\hline $\begin{array}{l}\text { 4. Adequado papel do líder do projeto } \\
\text { - Composição adequada do time do projeto. } \\
\text { - Documentação da visão do projeto (Planejamento, escopo, objetivos, organização, papéis e responsabilidades). } \\
\text { - Bom gerenciamento do escopo do projeto (Comitê diretor para avaliar mudanças). } \\
\text { - Desenvolvimento do projeto baseado em “milestones” (Questões comerciais com parceiros atreladas ao cumprimento de } \\
\text { - etapas). } \\
\text { - Tomadores de decisão capacitados e autorizados (Agilidade nas decisões). } \\
\text { - Equipe do projeto motivada. } \\
\text { - Conhestrutura e instalações para o projeto (Salas, computadores, redes). } \\
\text { - Adequado conhecimento dos sistemas legados (Migração dos dados). }\end{array}$ \\
\hline 5. Participação e comprometimento do usuário \\
\hline $\begin{array}{l}\text { 6. Parceiros com conhecimento e experiência } \\
\text { - Adequada estratégia de implementação do projeto (Entrada em operação, suporte). } \\
\text { - Adequada versão do software. } \\
\text { - Adequada configuração do software. } \\
\text { - Arquitetura técnica/performance inadequados. } \\
\text { - Utilização apropriada dos consultores (Como, quando, quantos). }\end{array}$ \\
\hline 7. Testes de aceitação do software \\
\hline 8. Bugs do software \\
\hline 9. Confiança entre parceiros do projeto \\
\hline
\end{tabular}


das discussões do projeto. Uma maneira de prepará-las é a apresentação antecipada dos novos sistemas e processos, enfocando as mudanças. Isso é conseguido por meio de um adequado programa de treinamentos. Assim, busca-se preparar antecipadamente tanto as equipes de implantação como os usuários finais.

Um fator importante para o sucesso do projeto é identificar as necessidades de informações das partes interessadas e determinar uma maneira adequada para atender a essas necessidades. Conforme Gambôa, Caputo e Bresciani Filho (2004), na implantação de um sistema ERP a comunicação formal sobre o projeto à organização é fundamental para o sucesso do projeto. As pessoas necessitam conhecer os objetivos do projeto, escopo e atividades previstas. Isso pode ser conseguido por meio de jornais internos, e-mails, quadro de avisos etc. 0 objetivo é que os funcionários tenham conhecimento das mudanças a caminho e se alinhem aos objetivos pretendidos para o negócio.

Ao terceiro FCS - "abrangente reengenharia do negócio" - foram incorporados três FCS: "customizações mínimas", "tamanho e complexidade do projeto" e "consenso em buscar o resultado bom o suficiente ao invés do resultado melhor disponível" (por vezes inalcançável).

0 nível de customização está relacionado ao desenho de negócio pretendido com o projeto. Para Esteves e Pastor (2000), uma organização deve tentar adaptar seus processos àqueles já construídos em um sistema ERP, ao invés de procurar mudar esse sistema para atender necessidades particulares de um negócio. Segundo os autores, é recomendável que as customizações, caso existam, sejam aderentes aos padrões suportados pelo software. Afirmam Esteves e Pastor (2000) que uma boa visão de negócios é útil porque reduz o esforço de se obter a funcionalidade do modelo de negócios do ERP, minimizando, desta forma, o esforço de customização.

0 tamanho e a complexidade do projeto também estão relacionados ao nível de mudança pretendido, ou seja, à reengenharia do negócio. Stackpole (2006) afirma que, baseado em experiências com implantação de sistemas ERP, para se ter sucesso em um projeto de sistema PLM deve-se perseguir o resultado bom o suficiente ao invés de o melhor disponivel. Durante a reengenharia do negócio esse aspecto é fundamental e demanda uma boa visão, conforme citado por Esteves e Pastor (2000).

Ao quarto FCS - "adequado papel do líder do projeto" - foram incorporados sete FCS: "composição adequada do time do projeto", "documentação da visão do projeto", "bom gerenciamento do escopo do projeto", "desenvolvimento do projeto baseado em milestones", "tomadores de decisão capacitados e autorizados", "equipe do projeto motivada", "infraestrutura e instalações para o projeto" e "conhecimento do software".

Com relação à composição adequada do time do projeto, é função da gerência observar as seguintes características ao selecionar os membros, internos ou externos, da equipe de implantação (PMBOK, 2004):

- Disponibilidade. Quem e quando estará disponível?

- Capacidade. Quais competências as pessoas possuem?

- Experiência. As pessoas já realizaram satisfatoriamente trabalhos semelhantes ou relacionados?

- Interesse. As pessoas estão interessadas em trabalhar no projeto?

- Custo. Quanto custará cada membro da equipe, especialmente se contratado de fora da organização?

Conforme Tondaladinne, Gurram e Bachala (2006), cabe à liderança do projeto elaborar e divulgar um documento de visão sobre a implantação de um sistema PLM. Esse documento contém uma visão clara das principais etapas do projeto, metodologia e fases de implantação, pontos de verificação, benefícios esperados e o retorno sobre o investimento.

Outro FCS endereçado à liderança do projeto é o bom gerenciamento do escopo. Ele apresenta os processos necessários para garantir que o projeto inclua todo o trabalho necessário e somente ele, para terminar o projeto com sucesso. 0 gerenciamento do escopo do projeto trata principalmente da definição e controle do que está e do que não está incluído no projeto.

Segundo Tondaladinne, Gurram e Bachala (2006), após selecionado o fornecedor de um sistema PLM o desenvolvimento do projeto deve conter milestones, nos quais são efetuados os pagamentos.

Stackpole (2006) afirma que o sucesso na implantação de um sistema PLM depende de membros da equipe de implantação que sejam tomadores de decisão. Cabe então ao líder do projeto identificá-los e prepará-los para esse fim.

Em relação à motivação da equipe, Russo et al. (2005) citam as várias habilidades de um líder que influenciam nas fases de gestão de um projeto. Muitas delas refletem diretamente no nível de motivação da equipe, como a autoconfiança, empatia, iniciativa, trabalho em equipe e cooperação, desenvolvimento dos demais etc. 
Com respeito à infraestrutura do projeto, cabe à liderança prever e providenciar todos os recursos necessários, como redes de informação, computadores, servidores, base de dados, ambiente para as equipes, para reuniões etc.

0 líder do projeto deve garantir que sua equipe tenha o conhecimento necessário do novo software a ser implantado. De acordo com o PMBOK (2004), se não for esperado que os membros da equipe a serem designados tenham as competências exigidas, será possível desenvolver um plano de treinamento como parte do projeto. 0 plano também pode incluir maneiras de ajudar os membros da equipe a obter certificações que beneficiariam o projeto.

Em relação ao adequado conhecimento dos sistemas legados, como em uma implantação de sistemas normalmente existe integração entre os sistemas novos e outros que permanecem em operação, cabe ao líder do projeto identificar os membros da equipe que detenham o conhecimento desses sistemas.

O quinto FCS - "participação e comprometimento do usuário” - não sofreu nenhuma alteração.

Ao sexto FCS - "parceiros com conhecimento e experiência” - foram acrescentados cinco FCS: "adequada estratégia de implementação do projeto”, “adequada versão do software”, “adequada configuração do software”, "arquitetura técnica/ performance inadequadas" e "utilização apropriada dos consultores”. Os cinco FCS são direcionados às empresas parceiras ou fornecedoras dos serviços de implantação, uma vez que compete a essas empresas a definição da metodologia de implantação, o conhecimento das versões adequadas dos sistemas a ser implantados, nível adequado de configuração desses sistemas, a definição da arquitetura de sistemas necessária e com performance adequada e a programação de atividades para cada consultor.

Os últimos três FCS - "testes de aceitação do software", "bugs do software" e "confiança entre parceiros do projeto" - não sofreram alteração.

\section{Priorização dos FCS}

Após identificação, validação e agrupamento dos FCS, foram identificadas as prioridades relativas de cada fator com relação às fases de implantação do projeto Fábrica Digital por meio da utilização combinada do método Delphi com o AHP. Na utilização do método Delphi foram seguidos os passos de Skulmoski, Hartman e Krahn (2007). Questionários foram elaborados com base na estrutura hierárquica do AHP e foram enviados pela internet a 17 participantes da pesquisa.
As atividades de implantação do projeto foram agrupadas em cinco fases, conforme descritas a seguir:

$1^{a}$ Fase - Preparação do projeto. Esta fase contempla as definições iniciais do projeto como planejamento geral, cronograma, escopo, objetivos, requisitos de negócio, parceiros, equipes, papéis e responsabilidades, softwares, hardwares e a arquitetura básica de funcionamento dos softwares. Aqui são aprovadas as aquisições mais significativas de softwares, hardwares e serviços. Também são iniciados os treinamentos para a equipe do projeto;

$2^{a}$ Fase - Definição dos processos futuros. Nesta fase é feito o mapeamento dos processos em prática na empresa, dos principais problemas, das oportunidades, dos requisitos funcionais e dos processos. Os parceiros (consultores) recomendam as melhores práticas a serem seguidas. São levantadas as diferenças entre os processos mapeados e as melhores práticas recomendadas, e definidos os planos para tratamento dessas diferenças. Também são identificadas as interfaces com os sistemas legados. 0 produto final aqui é a definição dos processos futuros a serem implantados;

$3^{a}$ Fase - Configuração do sistema. Nesta fase o sistema é configurado conforme os processos futuros, e os requisitos definidos na fase anterior. Os sistemas complementares e interfaces, caso existam, também são construídos. Documenta-se a configuração construída;

$4^{a}$ Fase - Testes de validação final e treinamento. Nesta fase são realizados os testes de integração da solução construída. 0 atendimento dos requisitos de negócios é validado. Toda a solução estabelecida na fase de definição dos processos futuros ( $2^{\text {a }}$ fase) é testada de forma integrada. Também têm início o treinamento dos usuários e o carregamento dos dados dos sistemas antigos para os sistemas novos;

$5^{a}$ Fase - Preparação para go live, go live e suporte. Nesta fase é planejado o início de operação da nova solução nos novos sistemas e com os novos processos. São desligados os sistemas antigos e acionados os novos. Equipes de suporte da Empresa A e da consultoria são preparadas para dar o apoio pós-implantação.

Embora inicialmente as cinco fases tenham sido definidas para o ciclo completo de implantação do projeto, elas podem ser definidas para etapas da implantação. Isso significa que pode-se ter as cinco fases aplicadas para uma porção da solução completa. Essa proposta viabiliza a utilização de partes da fábrica digital, antes de toda a implantação estar concluída. 
Para Shimizu (2006), o primeiro passo na construção da estrutura hierárquica de um problema é definir o objetivo global desejado. Para esta pesquisa esse objetivo foi definido como:

- Obter sucesso na implantação do projeto Fábrica Digital com relação a escopo, prazo, custo e qualidade.

A partir dessa definição, numa estrutura de árvore, conforme representado pela Figura 4, foram definidos os critérios, que são as fases de implantação do projeto:

- Fase 1: Preparação do projeto;

- Fase 2: Definição dos processos futuros;

- Fase 3: Configuração do sistema;

- Fase 4: Testes de validação final e treinamento;

- Fase 5: Preparação para go live, go live e suporte.

Em seguida foram relacionadas alternativas, definidas pelos seguintes FCS:

- FCS 1: Apoio e comprometimento contínuo da alta gerência;

- FCS 2: Gerenciamento efetivo da mudança ao longo do projeto (preparação das pessoas para a mudança);

- FCS 3: Abrangente reengenharia do negócio;

- FCS 4: Adequado papel do líder do projeto;

- FCS 5: Participação e comprometimento do usuário;

- FCS 6: Parceiros com conhecimento e experiência;

- FCS 7: Testes de aceitação do software;

- FCS 8: Bugs do software;
- FCS 9: Confiança entre parceiros do projeto.

A seguir são apresentadas as prioridades das fases e dos FCS do projeto e as principais análises destes resultados.

\section{Resultados}

Na Tabela 1 estão apresentados os valores das prioridades relativas de cada fase e de cada FCS em cada fase da implantação. Na última coluna estão os valores finais das prioridades relativas de cada FCS, ou seja, das prioridades compostas dos FCS, para o sucesso da implantação do projeto.

No resultado representativo do grupo, o FCS 1 - "apoio e comprometimento contínuo da alta gerência" - é o fator mais importante para o sucesso da implantação do projeto, com valor de prioridade relativa 0,151 . Contribuiu para esse resultado o fato de este fator ter se destacado como o de maior prioridade relativa na fase 1 - "preparação do projeto" (fase eleita a mais importante para o sucesso da implantação), com valor de prioridade relativa 0,199 e por ter ficado em segundo lugar, com valor de prioridade relativa 0,150 , na fase 2 - "definição dos processos futuros" (eleita como a segunda mais importante para o sucesso da implantação).

O FCS 3 - "abrangente reengenharia do negócio" - é o segundo fator mais importante para o sucesso da implantação do projeto, com valor de prioridade relativa 0,142 . Esse fator obteve o primeiro lugar em importância nas fases 2 - "definição dos processos futuros" - e 3 - "configuração do sistema” - com

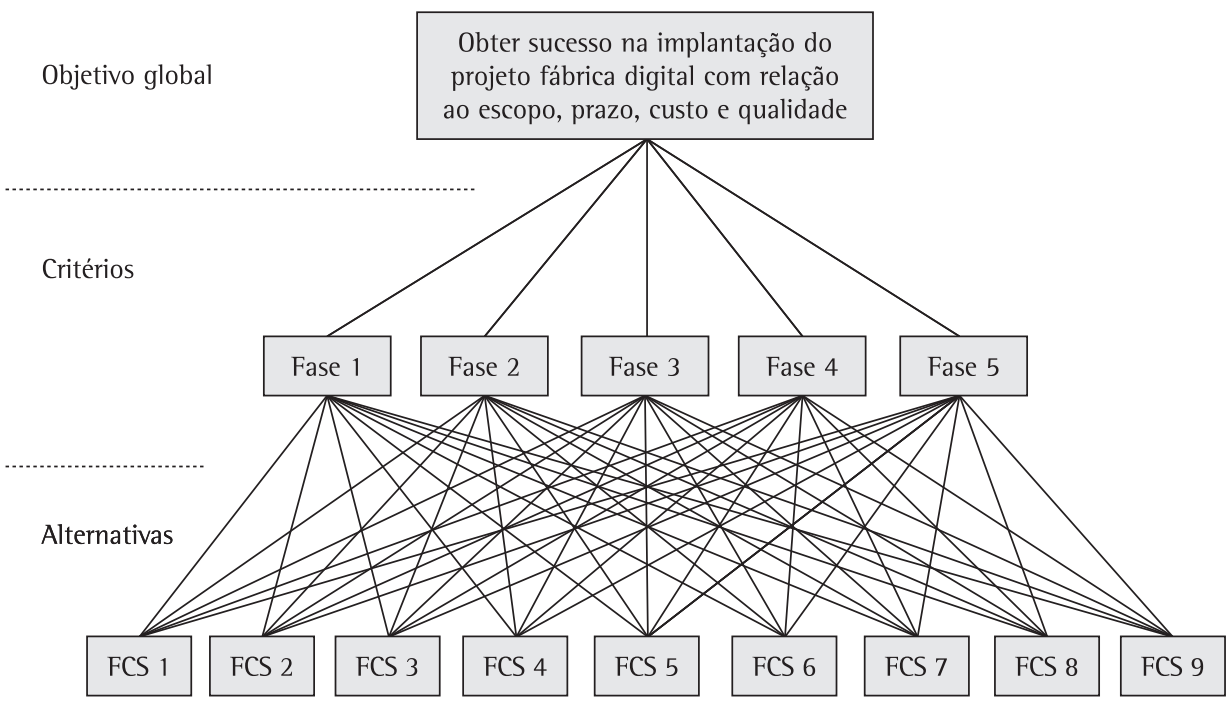

Figura 4. Estrutura hierárquica do problema. 
Tabela 1. Resultados das prioridades compostas dos FCS.

\begin{tabular}{|c|c|c|c|c|c|c|}
\hline & $\begin{array}{l}\text { 1- Preparação } \\
\text { do projeto }\end{array}$ & $\begin{array}{l}\text { 2- Definição } \\
\text { dos processos } \\
\text { futuros }\end{array}$ & $\begin{array}{l}\text { 3- Configuração } \\
\text { do sistema }\end{array}$ & $\begin{array}{l}\text { 4- Testes de } \\
\text { validação final } \\
\text { e treinamento }\end{array}$ & $\begin{array}{l}\text { 5- Preparação } \\
\text { para go live, } \\
\text { go live } \mathrm{e} \\
\text { suporte }\end{array}$ & $\begin{array}{l}\text { Prioridade } \\
\text { Composta }\end{array}$ \\
\hline & 0,357 & 0,338 & 0,152 & 0,095 & 0,059 & \\
\hline $\begin{array}{l}\text { 1- Apoio e comprometimento } \\
\text { contínuo da alta gerência }\end{array}$ & 0,199 & 0,150 & 0,103 & 0,068 & 0,128 & 0,151 \\
\hline $\begin{array}{l}\text { 2- Gerenciamento efetivo da } \\
\text { mudança ao longo do projeto } \\
\text { (Preparação das pessoas para } \\
\text { a mudança) }\end{array}$ & 0,104 & 0,113 & 0,130 & 0,089 & 0,108 & 0,110 \\
\hline $\begin{array}{l}\text { 3- Abrangente reengenharia } \\
\text { do negócio }\end{array}$ & 0,137 & 0,170 & 0,149 & 0,085 & 0,089 & 0,142 \\
\hline $\begin{array}{l}\text { 4- Adequado papel do líder } \\
\text { do projeto }\end{array}$ & 0,150 & 0,125 & 0,108 & 0,082 & 0,125 & 0,127 \\
\hline $\begin{array}{l}\text { 5- Participação e } \\
\text { comprometimento do usuário }\end{array}$ & 0,108 & 0,132 & 0,122 & 0,130 & 0,216 & 0,127 \\
\hline $\begin{array}{l}\text { 6- Parceiros com } \\
\text { conhecimento e experiência }\end{array}$ & 0,138 & 0,127 & 0,136 & 0,113 & 0,098 & 0,129 \\
\hline $\begin{array}{l}\text { 7- Testes de aceitação do } \\
\text { software }\end{array}$ & 0,047 & 0,050 & 0,083 & 0,192 & 0,079 & 0,069 \\
\hline 8- Bugs do software & 0,037 & 0,047 & 0,069 & 0,163 & 0,090 & 0,060 \\
\hline $\begin{array}{l}\text { 9- Confiança entre parceiros } \\
\text { do projeto }\end{array}$ & 0,078 & 0,086 & 0,100 & 0,078 & 0,067 & 0,084 \\
\hline Total & 1,000 & 1,000 & 1,000 & 1,000 & 1,000 & 1,000 \\
\hline
\end{tabular}

os valores de prioridade relativa 0,170 e 0,149 , respectivamente. Esse segundo lugar pode ser justificado uma vez que, caso as mudanças a serem implantadas sejam muito grandes e complexas, existe maior probabilidade de insucesso na implantação, especialmente quanto a prazos, custos e aceitação pelos usuários. Caso os processos desenhados e os requisitos definidos não sejam atendidos pelas funcionalidades padronizadas dos softwares, é necessário customizá-los, o que também pode aumentar o ciclo do projeto e colocar em risco o funcionamento de toda a solução.

Em terceiro lugar aparece o FCS 6 - "parceiros com conhecimento e experiência" -, com valor de prioridade relativa 0,129 . Esse FCS obteve o seu maior nível de importância na fase 3 - "configuração do sistema" -, ficando em segundo lugar com valor de prioridade relativa 0,136 . O terceiro lugar é justificado pelo fato de que, na implantação de um sistema, é esperado que a consultoria contratada para executar os serviços de implantação tenha conhecimento e experiência suficientes para conduzir as atividades conforme previsto em contrato e que traga as melhores práticas e as lições aprendidas de outras implantações, como forma de garantir o sucesso da nova implantação. Os consultores devem conhecer os softwares a ser implantados e dominar a metodologia a ser utilizada.
Ocupam juntos o quarto lugar o FCS 4 “adequado papel do líder do projeto" - e o FCS 5 "participação e comprometimento do usuário" -, com o mesmo valor de prioridade relativa 0,127 . 0 FCS 4 obteve sua maior importância na fase 1 - "apoio e comprometimento contínuo da alta gerência” -, ficando em segundo lugar, com valor de prioridade relativa 0,150. 0 quarto lugar para o papel do líder pode ser interpretado como adequado, quando consideradas suas principais responsabilidades. Seu papel inicia juntamente com as primeiras definições do projeto, sendo responsável por conduzir as aquisições de serviços e materiais de infraestrutura, escolha e preparação da equipe de implantação, divulgação do projeto, preparação da empresa para absorver as mudanças e o acompanhamento das atividades até a efetiva implantação. O FCS 5 obteve o primeiro lugar entre todos os fatores na fase 5 - "preparação para o go live, go live e suporte" - com valor de prioridade relativa 0,216 . 0 quarto lugar, no resultado geral se justifica, uma vez que, com a participação dos usuários durante a implantação, mais detalhes poderão ser considerados no desenvolvimento das novas práticas, enriquecendo a solução a ser implantada. Com esta participação os usuários poderão entender mais rapidamente as mudanças e, com isso, possíveis resistências aos novos processos e softwares poderão ser minimizadas. 
Quadro 4. Os três principais FCS nas fases de implantação.

\begin{tabular}{|l|c|c|c|c|c|}
\hline & $\begin{array}{c}\text { 1- Preparação } \\
\text { do projeto }\end{array}$ & $\begin{array}{c}\text { 2- Definição } \\
\text { dos processos } \\
\text { futuros }\end{array}$ & $\begin{array}{c}\text { 3- Configuração } \\
\text { do sistema }\end{array}$ & $\begin{array}{c}\text { 4- Testes de } \\
\text { validação final e } \\
\text { treinamento }\end{array}$ & $\begin{array}{c}\text { 5- Preparação } \\
\text { para go live, go } \\
\text { live e suporte }\end{array}$ \\
\cline { 2 - 6 } & $\left(1^{\circ}\right)$ & $\left(2^{\circ}\right)$ & $\left(3^{\circ}\right)$ & $\left.4^{\circ}\right)$ & $2^{\circ}$ \\
\hline $\begin{array}{l}\text { 1- Apoio e comprometimento } \\
\text { contínuo da alta gerência }\end{array}$ & $1^{\circ}$ & $2^{\circ}$ & & & \\
\hline $\begin{array}{l}\text { 2- Gerenciamento efetivo da } \\
\text { mudança ao longo do projeto } \\
\text { (Preparação das pessoas para } \\
\text { a mudança) }\end{array}$ & & & $3^{\circ}$ & & \\
\hline $\begin{array}{l}\text { 3- Abrangente reengenharia } \\
\text { do negócio }\end{array}$ & $2^{\circ}$ & $1^{\circ}$ & $1^{\circ}$ & & \\
\hline $\begin{array}{l}\text { 4- Adequado papel do líder } \\
\text { do projeto }\end{array}$ & & $3^{\circ}$ & & & $3^{\circ}$ \\
\hline $\begin{array}{l}\text { 5- Participação e } \\
\text { comprometimento do usuário }\end{array}$ & $3^{\circ}$ & & $2^{\circ}$ & & $1^{\circ}$ \\
\hline $\begin{array}{l}\text { 6- Parceiros com } \\
\text { conhecimento e experiência }\end{array}$ & & & & $1^{\circ}$ & \\
\hline $\begin{array}{l}\text { 7- Testes de aceitação do } \\
\text { software }\end{array}$ & & & & $2^{\circ}$ & \\
\hline 8- Bugs do software & & & & \\
\hline $\begin{array}{l}\text { 9- Confiança entre parceiros } \\
\text { do projeto }\end{array}$ & & & & & \\
\hline
\end{tabular}

Fonte: Dados da pesquisa.

Como o FCS 6 apresentou um valor de prioridade relativa $(0,129)$ muito próximo ao valor dos FCS 4 e $5(0,127)$, recomenda-se que esses três FCS sejam considerados com o mesmo nível de prioridade relativa.

Em quinto lugar fica o FCS 2 - "gerenciamento efetivo da mudança ao longo do projeto" (preparação das pessoas para a mudança) -, com valor de prioridade relativa 0,110 , indicando que para 0 grupo a preparação das pessoas para as mudanças tem um nível intermediário de importância para o sucesso do projeto.

O FCS 9 - "confiança entre parceiros do projeto" - fica em sexto lugar, com valor de prioridade relativa 0,084. Esse fator obteve níveis de importância bastante próximos em todas as fases do projeto, ficando sempre entre os três últimos fatores mais importantes em cada fase.

Em sétimo lugar fica o FCS 7 - "testes de aceitação do software" -, com valor de prioridade relativa 0,069 . Apesar dessa posição no resultado geral, esse fator foi considerado o mais importante na fase 4 - "testes de validação final e treinamento" -, com valor de prioridade relativa 0,192.

Na última posição, em oitavo lugar, fica o FCS 8 - "bugs do software" -, com valor de prioridade relativa 0,060 . Esse fator obteve o segundo lugar na fase 4 - "testes de validação final e treinamento" -, denotando que para o grupo, embora seja o de menor importância para o sucesso da implantação do projeto, é muito importante na fase 4.

0 Quadro 4 apresenta os três principais FCS para cada fase de implantação. Os valores $1^{\circ}, 2^{\circ}, 3^{\circ}, 4^{\circ} \mathrm{e}$ $5^{\circ}$, para as fases, representam a ordem decrescente de importância de cada fase para o sucesso da implantação do projeto. Os valores $1^{\circ}, 2^{\circ}, 3^{\circ}$, para os FCS, representam a ordem decrescente de importância dos mesmos em cada fase.

\section{Considerações finais}

Nos estudos sobre implantação de sistemas ERP, conduzidos por Esteves e Pastor (2000), o apoio da alta gerência também foi considerado o FCS de maior importância. Conforme citam os autores, alguns FCS identificados em seus estudos são clássicos e podem ser aplicados a outros tipos de implantações. Uma justificativa para esse fator ser considerado o mais importante é que a alta e média gerência têm o papel de garantir a alocação dos principais recursos ao projeto. Muitas vezes, pessoas imprescindíveis à implantação estão alocadas a outras atividades importantes na empresa. Cabe a esses gerentes decidir que as mesmas deixem suas atividades para participar do projeto. Também atuam nos casos de entraves quando estes ultrapassam a capacidade de solução da equipe de implantação. 
Uma das principais vantagens dos métodos MCDM é que estes reconhecem a subjetividade como inerente aos problemas de decisão e utilizam julgamento de valor como forma de tratá-la cientificamente (COSTA, 2006). Neste trabalho, o conhecimento e a experiência dos especialistas foram aspectos primordiais para os julgamentos de valor das fases e dos FCS, realizados por meio do AHP.

Alguns resultados deste trabalho foram incorporados à implantação do projeto na Empresa A e são descritos a seguir.

A participação efetiva dos principais patrocinadores desta empresa e do principal executivo da Empresa D acontece periodicamente, por meio de reuniões de acompanhamento, nas quais é apresentada a situação do projeto e são endereçadas as principais questões, que fogem ao poder de solução da equipe de implantação.

A busca pelas funcionalidades padronizadas do principal software se tornou uma constante ao longo da implantação. Elas devem ser apresentadas por consultores experientes em implantações, conhecedores da solução proposta. Este é um pré-requisito que se tornou obrigatório.

A solução final a ser implantada é o resultado do atendimento dos requisitos de negócio previamente definidos pela Empresa A e das recomendações da Empresa D. Portanto, os processos a serem implantados devem ser os mais adequados para a Empresa A, sob o ponto de vista das duas empresas.

A metodologia de implantação também é direcionada ao conhecimento e experiência dos consultores, que devem desenvolvê-la e apresentá-la para a equipe de implantação. Uma vez validada pela equipe da Empresa A, as duas empresas devem garantir a sua execução.

Uma proposta para a extensão dos estudos desenvolvidos neste artigo é a obtenção dos julgamentos das importâncias dos FCS, agrupados para as diferentes funções em uma implantação. Dessa forma poderia ser analisado como esses FCS são percebidos durante uma implantação por diretores e gerentes das empresas, líderes de projetos, líderes de equipes, usuários, parceiros de implantação e outros.

Outra proposta é a análise sobre a utilização efetiva dos FCS identificados e priorizados na implantação de um projeto de fábrica digital. Uma vez identificadas as implantações desse tipo de projeto já concluídas, que até a presente data não são conhecidas, torna-se possível investigar também se há novas considerações em relação a este artigo. Com a experiência então adquirida pelos especialistas, poderão ser identificados novos FCS, específicos para esse tipo de implantação.

\section{Referências}

ALVARENGA, M. L. F. Metodologia para verificação do sucesso na implantação de ERP (Enterprise Resources Planning) baseada nos fatores críticos de sucesso: aplicação na indústria mineira. 2003. 111 f. Dissertação (Mestrado em Engenharia de Produção) - Universidade Federal de Santa Catarina, Florianópolis, 2003.

CARALLl, R. A. The critical success factor method: establishing a foundation for enterprise security management. Pittsburgh: Carnegie Mellon University, 2004. (Technical Report CMU/SEl-2004-TR-010).

CARNEIRO, O. A. C. Fatores Críticos de Sucesso no lançamento (start-up) de pneus remoldados de automóveis, caminhonetas e seus rebocados leves certificados pelos organismos acreditados pelo INMETRO. 2006. 114 f. Dissertação (Mestrado em Sistemas de Gestão) Universidade Federal Fluminense, Niterói, 2006.

COSTA, H. G. Auxílio multicritério à decisão: método AHP. Rio de Janeiro: ABEPRO, 2006.

DALTON-TAGGART, R. The move to digital manufacturing. Tooling \&t Production, p. 30-32, 2005. Disponível em: <http://findarticles.com/p/articles/mi_qa5347/ is_200504/ai_n21369514/?tag=content;col1>. Acesso em: dez. 2009.

DIEHL, A. A.; TATIM, D. C. Pesquisa em ciências sociais aplicadas. métodos e técnicas. São Paulo: Pearson Prentice Hall, 2004.

ESTEVES, J.; PASTOR, J. Towards the unification of critical success factors for ERP implementations. In: ANNUAL BUSINESS INFORMATION TECHNOLOGY, 10., 2000, Manchester. Anais... Disponivel em: <http://www. jesteves.com/bit2000.pdf>. Acesso em: dez. 2009.

GAMBÔA, F. A. R.; CAPUTO, M. S.; BRESCIANI FILHO, E. Método para gestão de riscos em implementações de sistemas ERP baseado em fatores críticos de sucesso. Revista de Gestão da Tecnologia e Sistemas de Informação, v. 1, n. 1, p. 44-61, 2004.

KElL, M. et al. A framework for identifying software project risks. Communications of the $A C M$, v. 41, n. 11, p. 76-83, 1998.

KRASNER, H. Ensuring E-Business Success by Learning from ERP Failures. IT Professional, v. 2, n. 1, p. 22-27, 2000.

KUEHN, W. Digital factory: integration of simulation enhancing the product and production process towards operative control and optimisation. International Journal of Simulation, v. 7, n. 7, p. 27-29, 2006.

LAURINDO, F. J. B. Tecnologia da informação: eficácia nas organizações. São Paulo: Futura, 2002.

MATOS, M. M. Metodologia de análise de impactos após a implementação de sistemas de gestão empresarial. 2004. 159 f. Dissertação (Mestrado em Engenharia de Produção) - Universidade Federal de Santa Catarina, Florianópolis, 2004.

MCAFEE, A. Mastering the Three Worlds of Information Technology. Harvard Business Review, v. 84, n. 11 , p. 85-93, 2006 
MORAES, R. 0.; LAURINDO, F. J. B. Um estudo de caso de gestão de portfólio de projetos de tecnologia da informação. Gestão e Produção, v. 10, n. 3, p. 311-328, 2003.

PAVANI, L. Usando simulação 3D, a Volkswagen reduziu em 1 milhão de reais os custos de desenvolvimento de novos veículos: e isso é só o começo. Info Corporate, n. 36, 2007.

PMBOK Guide. A Guide to the Project Management Body of Knowledge. 3 ed. Estados Unidos: PMI, 2004.

QUINTELLA, H. L. M. M.; ROCHA, H. M.; ALVES, M. F. Projetos de veículos automotores: fatores críticos de sucesso no lançamento. Produção, v. 15, n. 3, p. 334-346, 2005.

ROCHA, H. Fatores Críticos de Sucesso de Start-up de Veículos e a Qualidade (CMMI) no Desenvolvimento de Produtos no Sul Fluminense. 2005. 353 f. Dissertação (Mestrado em Sistemas de Gestão) - Universidade Federal Fluminense, Niterói, 2005.

ROCKART, J. Chief executives define their own data needs. Harvard Business Review, v. 57, p. 81-83, 1979.

ROWE, J. Digital factory within reach: modular options mean even SMBs can take advantage of production and manufacturing visualization tools. MCAD Tech News, n. 179, 2006. Disponível em: <http://www.cadalyst.com/ manufacturing/news/mcad-tech-news-179-11698>. Acesso em: dez. 2009.
RUSSO, R. F. S. M.; RUIZ, J. M.; CUNHA, R. P. Liderança e influência nas fases da gestão de projetos. Revista Produção, v. 15, n. 3, p. 362-375, 2005.

SAATY, T. L.; PENIWATI, K. Group decision making: drawing out and reconciling differences. Pittsburgh: RWS, 2008.

SHIMIZU, T. Decisão nas organizações. 2 ed. São Paulo: Atlas, 2006.

SKULMOSKI, G. J.; HARTMAN, F. T.; KRAHN, J. The Delphi Method for Graduate Research. Journal of Information Technology Education, v. 6, p. 1-22, 2007.

SLANSKY, D. Gaining competitive advantage through digital manufacturing. ARC Insights, v. 2006-11EC, p. 1-4, 2006.

STACKPOLE, B. Bringing PLM into Focus. Managing Automation Magazine, p. 1-2, 2006.

TONDALADINNE, S. S.; GURRAM, S.; BACHALA, S. Product Lifecycle Management Challenges: From Solution Evaluation to Kickoff. Technology Evaluation Centers, 2006.

WALLENIUS, J. et al. Multiple Criteria Decision Making, Multiattribute Utility Theory: recent accomplishments and what lies ahead. Management Science, v. 54, n. 7, p. 1336-1349, 2008.

WAURZYNIAK, P. Enter the Virtual World. Manufacturing Engineering. ABI/INFORM Global, v. 139, n. 4, p. 67, 2007.

\title{
Identification and prioritization of critical success factors in a digital factory implementation
}

\begin{abstract}
A Digital Factory is a concept which improves the collaboration among product development processes. Despite the benefits brought by this concept, failures may occur in its implementation. This paper aims to present the Critical Success Factors in the implementation of a Digital Factory project in a Brazilian company. These factors were identified by an exploratory survey on the implementation of Enterprise Resource Planning and Product Lifecycle Management among other systems. Following this identification, the factors were prioritized using the Delphi Method and the Analytic Hierarchy Process; this evaluation was carried out by professionals from enterprises which implement Digital Factory projects, in Brazil and abroad. Nine factors were identified. The five main priorities were: Continuous Support and Commitment from Top Management; Comprehensive Business Reengineering; Skilled and Experienced Partners; Participation and Commitment of Users; and Appropriate Role of the Project Manager.
\end{abstract}

Keywords

Digital factory. Critical success factors. Delphi method. AHP. 